This item was submitted to Loughborough's Research Repository by the author.

Items in Figshare are protected by copyright, with all rights reserved, unless otherwise indicated.

\title{
Eye hazards of laser 'pointers' in perspective
}

PLEASE CITE THE PUBLISHED VERSION

http://dx.doi.org/10.1136/bjophthalmol-2016-308798

PUBLISHER

() British Medical Journal Publishing Group

VERSION

AM (Accepted Manuscript)

PUBLISHER STATEMENT

This work is made available according to the conditions of the Creative Commons Attribution-NonCommercialNoDerivatives 4.0 International (CC BY-NC-ND 4.0) licence. Full details of this licence are available at: https://creativecommons.org/licenses/by-nc-nd/4.0/

\section{LICENCE}

CC BY-NC-ND 4.0

\section{REPOSITORY RECORD}

Marshall, J., John B. O'Hagan, and John Tyrer. 2019. “Eye Hazards of Laser 'pointers' in Perspective”. figshare. https://hdl.handle.net/2134/23488. 
Title: Eye Hazards of Laser "Pointers" in perspective

Marshall J, O’Hagan JB, Tyrer JR.

Corresponding author.

Professor John Marshall, UCL, Institute of Ophthalmology, 11-43 Bath

Street, London EC1V 9EL

Eye.marshall@googlemail.com

07802157156

Professor John Marshall,

FMedSci, FRCPath, FRSB, FRCOphth (Hon), FCOptom (Hon), FARVO, FLIA, FRSA

University College London, Institute of Ophthalmology, 11-43 Bath

Street, London, EC1V 9EL, UK.

Member of BSi committee for laser safety.

John B O'Hagan PhD

Public Health England, Chilton, Didcot, Oxfordshire, UK.

Laser and Optical Radiation Dosimetry Group, Public Health England, Chilton, UK; Chairman, Laser Safety BSI Committee EPL/76;

Professor John R Tyrer, FIMechE, FLIA

Professor of Optical Instrumentation,

Department of Mechanical and Manufacturing Engineering

Loughborough University, Loughborough, Leicestershire, LE11 3TU, UK

Member of BSI committee for laser safety. 
Eight years ago media coverage of incidents involving laser pointers in which individuals claimed to have suffered eye damage resulted in a perspective being published in this journal (1). The final sentence concluded "laser pointers, pens or keyrings if used appropriately are not an eye hazard, and even if used inappropriately will not cause permanent eye damage". This statement has been supported by the finding that until recently no irreversible eye injuries had been reported for a period of almost 15 years other than those caused by deliberate and prolonged viewing of laser beams (2). During this time period pointers have been freely available with an estimated 500,000 to $\mathrm{c} 1.2$ million laser pointers in circulation.

Unfortunately this is now not the case. Whilst the biophysics relating to eye injuries remains constant the nature and supply of current handheld devices have changed dramatically in the past eight years. In the past pointers predominantly produced red laser beams and were restricted to have an upper output limit of $1 \mathrm{~mW}$ and as such were classified as Class 2 laser products. Safety was afforded by insufficient energy being able to pass into the eye before the targeted individual blinked and turned their head. In reality as a result of both increased efficiency of modern devices and poor manufacturing compliance many of these devices classified as Class 2 have outputs of between 0.5 and $300 \mathrm{~mW}$. Clearly they are mislabelled and should have been identified as Class 3B laser products, which are not appropriate for general sale to the public..

Today, low-cost laser "pointers" producing green or red laser beams with output powers of $1000 \mathrm{~mW}$ can be found and indeed devices on the Internet of between 1500 and $6000 \mathrm{~mW}$ are commercially available. These Class 4 devices are capable of causing irreversible retinal damage if directed into the eye over short ranges, up to several metres. Such devices have resulted in foveal injuries in children(3) with current estimates of 150 cases in the UK. The media has given significant coverage to this growing problem. It should be remembered that therapeutic applications of lasers to the retina are typically within the 70 to $120 \mathrm{~mW}$ range.

A second group of media reports concern beams from handheld lasers being directed at fixed wing aircraft and helicopters. In this situation the systems are operating over a long-range - typically hundreds to thousands of metres and the laser beam has to pass through the atmosphere before traversing a cockpit canopy or 
windshield. These are usually pitted or scratched and will serve to scatter the primary beam and may result in the generation of secondary and tertiary beams. In these situations pilots tend to selffocus on a sudden bright light in the cockpit environment and may be dazzled resulting in an after-image and almost certainly will be distracted. Obviously if such a distraction occurs at a critical time such as during landing then the result could be devastating. Fortunately these exposures are at irradiances that are incapable of producing irreversible retinal damage even at distances of a hundred metres.

Thus ophthalmologists will be presented with two totally different ocular exposures: in the first case exposures derived from close proximity such as children playing together or individuals deliberately confronting a line of policemen. In such cases potential irreversible damage may have occurred and would merit a detailed examination if a permanent scotoma had been reported. These injuries are usually uni-ocular. Obviously no treatment would be available but the examination may be helpful in relation to future prevention. Whenever possible step should be undertaken to secure the causal device or at least record any defining parameters known as this would be helpful in terms of any ensuing litigation or prosecution.

By contrast in the second situation both eyes may be involved but subsequent to the dazzle and any after images resolving and no permanent abnormalities being reported on an Amsler grid any detailed fundal examination would only serve to compromise the pilot's vision for a longer period.

Only one case of alleged retinal damage to a pilot resulting from laser targeting of aircraft has been reported(4), although not in a peer review ophthalmic journal. This case is suspect because first and foremost, the metrology and exposure geometry would suggest insufficient energy could have entered the eye to produce irreversible damage and secondly the fundus anomaly is in the wrong location, the wrong shape and resulted in an extremely transient reported loss of VA with full recovery. Fortunately, with the exception of this suspect report, there have been no other recorded incidents of permanent damage resulting from directing "laser pointers" at the aircraft. The practice is however totally unacceptable given the potential consequences of distracting a pilot at a critical 
time and has now resulted in prosecutions and in some cases prison sentences. Unfortunately even with the possibility of custodial sentences such incidents are on the increase with more than 1500 such incidents being reported in the last 12 months within the UK.

The profession should be reassured that Standards and international Guidelines to protect individuals against laser radiation are based on extensive empirical data derived from exposures in monkeys and cross-checked with exposures in man in eyes enucleated as a result of anterior malignant melanomas. Like most safety documents ED 50 s for laser damage have been derived from thousands of exposures in empirical studies using an endpoint of fundoscopy. Further thresholds at more sensitive levels have been determined using fluorescein angiography, histology and electron microscopy(5). The Standards consider wavelength, pulse duration, spot size, irradiance and multiple pulses and these parameters have been taken into account in terms of classifying lasers for ease in identifying their potential hazard $(6,7)$. There is almost universal international agreement between such Standards and they have made a major contribution to public safety. Contrary to media concern they do not need revision but clearly further attempts must be made to educate the public.

All laser pointer incidents and virtually all laser accidents in research laboratories and industry are self-reported. In laboratories and industry, accidents are predominantly related to infrared laser beams that do not initiate a visual response and the victim is often unaware of the exposure unless ocular symptoms present. In the present laser pointer scenario the individual who has been inadvertently or deliberately exposed to laser light will be aware of exposure as such beams are in the visible range, $400 \mathrm{~nm}$ to $700 \mathrm{~nm}$. Because of the spectral sensitivity curve of the retina a green laser beam of equal energy to a red beam will be perceived to be far brighter and as a consequence will result in a greater degree of dazzle, although there will be relatively little difference in terms of retinal damage if the threshold is exceeded. Close quarter injuries are almost always uni-ocular and will usually be described as a dazzling flash inducing blinking or temporary lid closure followed by an after-image. Bilateral injuries had been reported because of deliberate exposure. As a result of media coverage some individuals may experience an element of psychological fear that their eyes have been permanently damaged and that they will be "blinded". It should 
be remembered that at close ranges the retinal image will be in the order of 25-100 microns and because of the natural response to direct the fovea at the bright source any damage will usually result in a central scotoma. Typically individuals will present to an eye clinic or an eye care professional within hours of the exposure. Clinically the first test is an Amsler grid or other test of central vision. By contrast, exposures of pilots to beams from currently available lasers over long ranges and to scattered beams due to cockpit canopies may still produce dazzle and disorientation but not permanent scotomas. In many cases the multiple beams produced by cockpit canopies may result in further sources of reflection within the cockpit and bilateral exposures. In these cases presentation to eye care specialists may occur after delays of many hours or a day or so during which there may be a growing psychological element. Again a test of central vision is the most useful approach and if no visual decrement is determined then further examination of the fundus may not be helpful.

The European Commission has mandated the European Standardisation bodies to produce a standard specifically for consumer laser products. This should allow enforcing authorities to remove unsafe products from the market. However, compliance by manufacturers will remain an issue, as will direct imports by the public purchasing unsafe laser products over the Internet.

References:

1 Marshall J. The safety of laser pointers: myths and realities. $\mathrm{Br} J$ Ophthalmol 1998;82(11):1335-1338.

2 Mainster MA, Stuck BE, Brown J. Assessment of Alleged Retinal Laser Injuries. Arch Ophthalmol. 2004;122:1210-1217

3 Raoof N, Chan TK, Rogers NK et al. 'Toy' laser macular burns in children. Eye (Lond) 2014;28(2):231-234

4 Gosling DB, O'Hagan JB \& Quhill FM. Blue laser-induced retinal injury in a commercial pilot at $1300 \mathrm{ft}$. Aerosp Med Hum Perform. 2016;87(1):69-70.

5 Borland R G, Brennan D H, Marshall J et al. The role of fluorescein angiography in the detection of laser-induced damage to the retina: a threshold study for Q-switched, neodymium and ruby lasers. Exp Eye Res 1978;27(4): 471-493. 
6 BSI 2014. Safety of Laser Products. Part 1: Equipment classification and requirements. BS EN 60825-1: 2014, British Standards Institution, London.

7 ICNIRP Guidelines on Limits of Exposure to Laser Radiation of Wavelengths between $180 \mathrm{~nm}$ and 1,000 $\mu \mathrm{m}$. Health Physics 2013;105(3):271-295. 